OPEN ACCESS

Edited by:

Pasquale De Palo,

University of Bari Aldo Moro, Italy

Reviewed by:

Arda Yildirim

Gaziosmanpaşa University, Turkey

Asad Sultan,

University of Agriculture, Pakistan

*Correspondence:

Amarachi Chijioke Ogbonna a.ogbonna2@ncl.ac.uk

Specialty section:

This article was submitted to Animal Welfare and Policy,

a section of the journal

Frontiers in Animal Science

Received: 01 November 2021 Accepted: 13 December 2021

Published: 17 January 2022

Citation:

Ogbonna AC, Chaudhry AS and Asher L (2022) Effect of Dietary Vitamin D3 and Ultraviolet B Light on Growth Performance, Blood Serum

Parameters, Gut Histology, and

Welfare Indicators of Broilers.

Front. Anim. Sci. 2:806967. doi: 10.3389/fanim.2021.806967

\section{Effect of Dietary Vitamin D3 and Ultraviolet B Light on Growth Performance, Blood Serum Parameters, Gut Histology, and Welfare Indicators of Broilers}

\author{
Amarachi Chijioke Ogbonna ${ }^{1,2 *}$, Abdul Shakoor Chaudhry ${ }^{1}$ and Lucy Asher ${ }^{1}$ \\ ${ }^{1}$ Agriculture Building, School of Natural and Environmental Sciences, Newcastle University, Newcastle upon Tyne, \\ United Kingdom, ${ }^{2}$ Department of Animal Production and Livestock Management, College of Animal Science and Animal \\ Production, Michael Okpara University of Agriculture, Umudike, Nigeria
}

Stressors are commonly encountered by all farmed species, including chickens, but the impact of these stressors on the animal and their productivity can be influenced by the environmental conditions in which they are kept. This study investigated the effects of dietary vitamin $\mathrm{D} 3\left(\right.$ vit $\left._{3}\right)$ and ultraviolet light (UVB) on growth performance, organ weight, serum corticosterone levels (CORT), serum 25-hydroxy vitamin D $\left(25-\mathrm{OH}-\mathrm{D}_{3}\right)$ status, gut histology, and welfare indicators of broiler chickens challenged with social isolation stress. One day (d) old Ross 308 broiler chicks $(n=192)$ were individually weighed, wing-tagged, and allocated to non-isolated (control) and isolated groups; control birds were never isolated, while isolated birds were subjected to regular sessions of social isolation for about 15-min periods over the course of $3 \mathrm{~d}$ a week for 2 weeks starting from d 10 ( $1.30 \mathrm{~h}$ total exposure) with inter treatment interval of $48 \mathrm{~h}$. Birds were treated with either dietary vitD 3 at $4,000 \mathrm{IU} / \mathrm{kg}$ (HD) or UVB light (UVB). The UVB lamp (24 Watt 12\% UVB D3, $55 \mathrm{~cm}$ ) with wavelength: $280-315 \mathrm{~nm}$, intensity; 28.12 $\mu \mathrm{W} / \mathrm{cm}^{2}$ hung $50 \mathrm{~cm}$ above the substrate was used for the broilers in all the treatment groups but were filtered to remove UVB in the HD group. Growth performance measure; body weight gain, feed intake, and feed conversion ratio were estimated at the end of starter (day 10), grower (day 24), and finisher periods (day 38). Broilers were feather and gait scored to measure welfare at $22 / 35$ and $24 / 37$ days of age, respectively. The selected birds were weighed and euthanized to obtain serum to determine $25-\mathrm{OH}-\mathrm{D}_{3}$ and CORT levels, GIT weights, and gut histology. Subjecting the birds to 2-week social isolation (for $15 \mathrm{~min}$, three times per week) increased CORT levels but did not alter GP and $25-\mathrm{OH}-\mathrm{D}_{3}$ levels of broilers. However, UVB-treated broilers demonstrated better welfare, duodenal absorptive capacity, and reduced FCR compared to HD chickens. Results suggest some beneficial effects of UVB lighting on welfare indicators and the potential to support early life growth of commercial broilers reared indoors, which are often challenged with stressors.

Keywords: broiler, dietary vitamin $D_{3}$, UVB light, isolation, stressors, performance, welfare 


\section{INTRODUCTION}

Within commercial intensive poultry production, chickens are vulnerable to constant environmental challenges and management-associated stressors. Management-associated stressors and challenges include hatching without maternal contact, capturing, handling, transportation, extreme temperatures, social disruption, unfamiliar sounds and handlers, feed and water restriction (Zulkifli, 2013). These may cause stress (Frazer and Broom, 1990; Kannan and Mench, 1996; Bortolotti et al., 2008; Alm et al., 2014), leading to reduced performance and increased susceptibility to diseases (Goerlich et al., 2012) with secondary impacts on welfare (Carvalho et al., 2018).

Any deviation from the normal body processes can be considered stress, which occurs as a physiological response to an environmental stressor or changes or challenges to re-establish homeostatic integrity within the body (Lara and Rostagno, 2013). Stress can cause structural changes in different parts of the body system, bringing about differences in response to stress. The rate of effect of stress differs according to the stress level, duration (Lupien et al., 2009), and stage of life (Arakawa, 2003).

Different environmental management approaches such as improving house conditions (Deep et al., 2010), reducing the stock density (Buijs et al., 2009), environmental enrichment (Ventura et al., 2010) or artificial selection for reduced growth rate (Decuypere et al., 2010) have been reported to promote the performance of broiler chickens while reducing the stress responses. Therefore, an improvement in production parameters and efficiency depends on the quality of the environmental management techniques. The potential of dietary vitamin $\mathrm{D}_{3}$ $(\text { vitD })_{3}$ ) and ultraviolet-B (UVB) light to influence broiler feed efficiency, growth and welfare is gaining considerable recognition (Edwards, 2003; Zhang et al., 2006; James et al., 2018) but has not been studied extensively. Therefore, it is necessary to assess and establish the best strategy for the provision of vitD $\mathrm{D}_{3}$.

Vitamin $\mathrm{D}_{3}\left(\mathrm{VitD}_{3}\right)$, known as cholecalciferol $\left(\mathrm{D}_{3}\right)$, is the inactive form of vitamin D. It is an essential nutrient important for growth and development with a close relationship between nutrition and health (Chou et al., 2009). It can be absorbed from the diet through dietary supplementation or be generated endogenously in the skin of animals exposed to sunlight through the chemical conversion of 7-dehydrocholesterol to cholecalciferol (Slominski et al., 2010; Li et al., 2014). However, an industry-standard broiler house in the UK involves the use of controlled, indoor housing with little exposure of birds to natural sunlight, inhibiting the ability of the skin to produce endogenous vit $\mathrm{D}_{3}$, while raw materials in broiler diets contain little or no vitD 3 (Atencio et al., 2005). As a result, vitD requirements are supplemented in the diet. Although windows may be incorporated into poultry houses, they may not transmit UVB for vitD $\mathrm{D}_{3}$ synthesis in broilers (Duarte et al., 2009). Additionally, continuous artificial light illuminations provided are weak ultraviolet (UV) emitters (Lewis and Morris, 1998). UV environment has been found to be associated with stress hormone concentrations, with corticosterone found to be higher in chicks raised in UV deficient conditions (Maddocks et al., 2001).
Light is considered one of the most important environmental parameters in poultry production, not only providing illumination for the birds but also regulating many physiological processes (Olanrewaju et al., 2016; Rault et al., 2016; Soliman and El-Sabrout, 2020). Broilers possess a super visual eye system that allows them to see through UV light (wavelength shorter than $400 \mathrm{~nm}$ ), which is invisible to humans (Akyüz and Onbasilar, 2018). Previous research on UV light reported improved welfare (Zhang et al., 2006; Slominski et al., 2010; James et al., 2018; Ogbonna et al., under review), reduced corticosterone (CORT) levels in chickens (Maddocks et al., 2001; House et al., 2020a) and Pekin ducks (House et al., 2020b) although such studies did not provide comparisons with dietary vit $\mathrm{D}_{3}$. Thus, it is not clear whether the impacts arise from the benefits of UV lighting or the secondary benefits of vitD 3 synthesis.

Extensive research has investigated the effects of social isolation in other animal populations (Mendoza and Mason, 1986; Rukstalis and French, 2005; Chauke et al., 2011) with a few in broiler chickens (Goerlich et al., 2012; Weldon et al., 2016). Therefore, this study focused on the effects of dietary vit $\mathrm{D}_{3}$ and UVB light source on growth performance, CORT, 25-OH$\mathrm{D}_{3}$ status, gastrointestinal tract (GIT) component weights, gut histology and welfare indicators of broiler chickens challenged with social isolation. Such investigations may provide evidence of whether dietary vit $\mathrm{D}_{3}$ or UVB light exposure exerts dual roles in broilers following a physiological challenge by improving growth performance, $25-\mathrm{OH}-\mathrm{D}_{3}$ status, health and welfare while reducing CORT. Understanding the effects of stress on broiler traits, the basis of the stress response, and the role of vitD 3 source support against social isolation stress is critical in highlighting novel opportunities to promote broiler performance, health and welfare. This study tests the hypothesis that UVB light supplementation would increase production parameters such as feed conversion ratio (FCR) and improve broiler health and welfare by decreasing CORT.

\section{MATERIALS AND METHODS}

\section{Ethics Statement}

All procedures were conducted in accordance with the ethics and provisions of the UK Animals (Scientific Procedures) Act 1986 after obtaining approval from the Animal Welfare and Ethical Review Body (AWERB), Newcastle University, (AWERB ID: 806).

\section{Birds, Housing, Husbandry, and Diets}

A total of 192 one-day (d) old Ross 308 chicks procured from P D Hook Hatcheries Limited, United Kingdom, were used for this experiment. Upon arrival, the chicks were individually weighed, wing-tagged, and randomly allocated to 1 of 32 identical rectangular pens $(1 \times \mathrm{w} \times \mathrm{h}: 140 \times 60 \times 100 \mathrm{~cm})$, respectively. The pens had been assigned 1 of 4 treatments and divided into two social isolation stress statuses, viz; non-isolated (control) and isolated. All broilers were treated with either dietary vitD $\mathrm{D}_{3}$ at $4,000 \mathrm{IU} / \mathrm{kg}$ only (HD) or UVB light wavelength (UVB) so that each treatment had eight replicate pens containing six broilers per pen in a $2 \times 2$ factorial design. During the experiment, the 

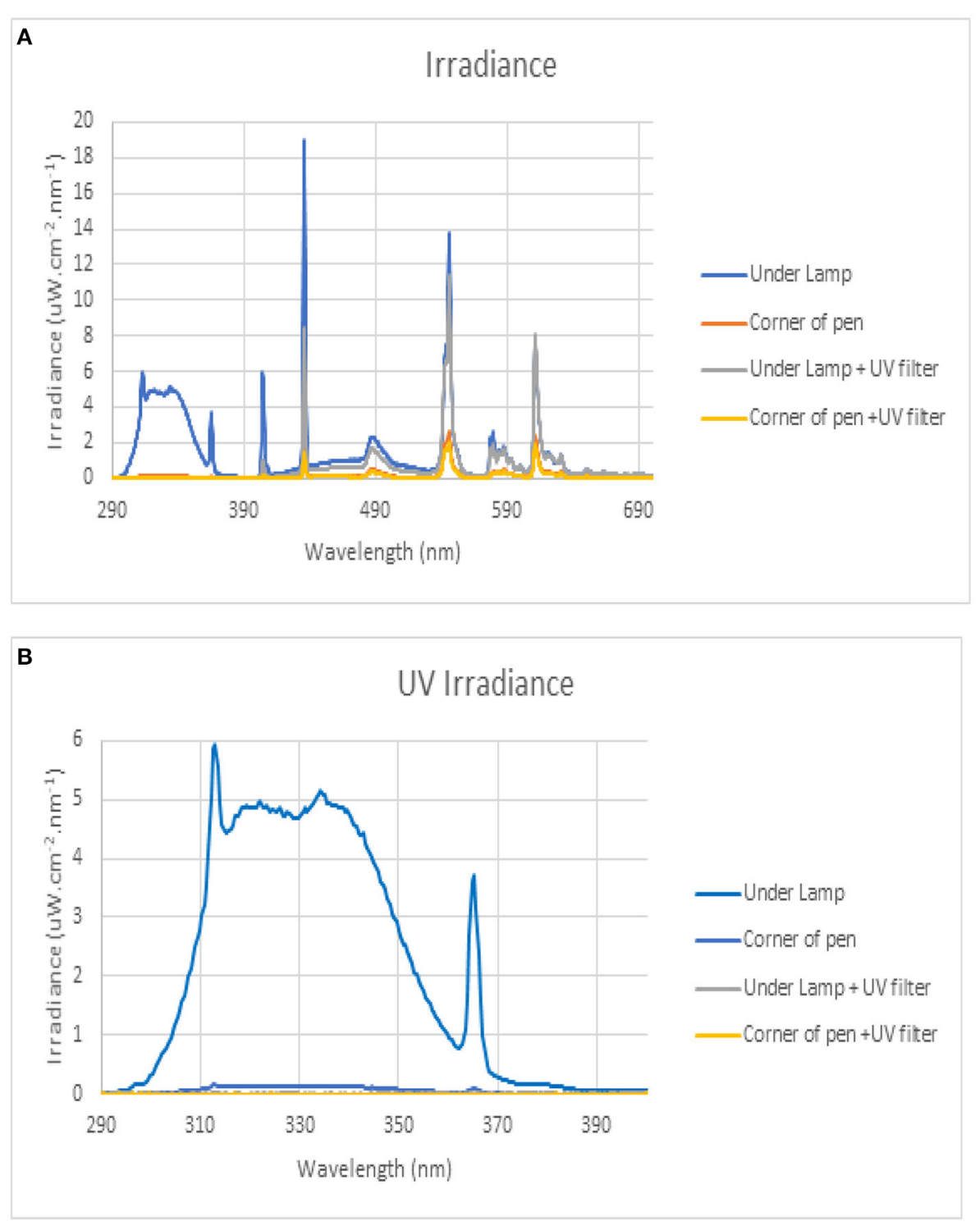

FIGURE 1 | (A) The Irradiance $\left(\mu \mathrm{W} / \mathrm{cm}^{2}\right)$ of wavelengths $(\mathrm{nm})$ in the HD treated group. (B) The Irradiance $\left(\mu \mathrm{W} / \mathrm{cm}^{2}\right)$ of wavelengths $(\mathrm{nm})$ in the UVB treated group.

birds were housed in a windowless, thermostatically controlled building equipped with feeders and drinkers, and wood shavings were used as litter to a depth of $5 \mathrm{~cm}$ covering the entire concrete pen floor. The temperature at pen level was monitored daily and maintained to meet Aviagen recommendations for spot brooding (Aviagen, 2019), starting at $34^{\circ} \mathrm{C}$ at chick placement $\mathrm{d} 0$, and gradually brought down to $22^{\circ} \mathrm{C}$ by d 13 where it was maintained until $38 \mathrm{~d}$ of age when the trial was terminated. The heat was supplemented with dull emitter ceramic bulbs. Light intensity at pen level was $80 \mathrm{~lx}$ while a lighting program of $23 \mathrm{~h}$ (h) (23L:1D) of light and $1 \mathrm{~h}$ of darkness was applied from $\mathrm{d} 0$ to $7 \mathrm{~d}$ of age, followed by $18 \mathrm{~h}$ (18L:6D) of light for the remainder of the trial. All the birds in the four treatment groups were treated with the UVB light from a $55 \mathrm{~cm} 24 \mathrm{~W} 12 \% \mathrm{UVB}_{3}$ output lamp (Arcadia Products plc, Surrey, UK) as the lighting program which was installed in the centre of the pen at $50 \mathrm{~cm}$ above the substrate throughout the rearing period. Each UVB lamp provided a UVB intensity of $28.12 \mu \mathrm{W} / \mathrm{cm}^{2}$ as determined by a spectrometer FLAME-S-XR1-ES (International light technologies ILT 1400A) over the wavelength range of $280-315 \mathrm{~nm}$, but it was filtered using CONTROL-CURE ${ }^{\circledR}$ UV blocking films (Epak Electronics, Somerset UK) to remove UVB radiation in the HD groups only. The Irradiance $\left(\mu \mathrm{W} / \mathrm{cm}^{2}\right)$ of wavelengths $(\mathrm{nm})$ in each treatment are shown in Figures 1A,B. Appropriate starter crumbs, grower pellets, and finisher pellets were provided ad libitum to suit the size and age of the experimental chicks. All chicks had ad libitum access to fresh drinking water and feed, replenished throughout the experimental period. A basal starter diet (d 0-10) prepared in crumbled form, grower diet (d 11-24), and finisher diet (d 2538) prepared in pelleted form were formulated and manufactured 
TABLE 1 | Ingredients and analysed chemical composition of the basal starter (d 0-10 post-hatch), grower (d 11-d24) and finisher (d 25-d38) diets offered to broiler chickens

\begin{tabular}{|c|c|c|c|}
\hline Ingredients & Starter & Grower & Finisher \\
\hline Wheat & 47.9 & 51.5 & 54.8 \\
\hline Soybean meal (48\% CP) & 32.1 & 25.3 & 18.7 \\
\hline Corn & 10.0 & 10.0 & 10.0 \\
\hline Soybean full fat & 4.00 & 7.00 & 10.0 \\
\hline Dicalcium phosphate & 1.89 & 1.66 & 1.46 \\
\hline Soy crude oil & 1.84 & 2.32 & 2.86 \\
\hline Limestone & 0.64 & 0.59 & 0.54 \\
\hline Vitamin and mineral premix $x^{a, b}$ & 0.40 & 0.40 & 0.40 \\
\hline DL-methionine & 0.33 & 0.30 & 0.25 \\
\hline L-Lysine & 0.21 & 0.26 & 0.25 \\
\hline Sodium bicarbonates (27\%) & 0.21 & 0.20 & 0.21 \\
\hline Sodium chloride (39\%) & 0.19 & 0.21 & 0.21 \\
\hline L-Threonine & 0.14 & 0.12 & 0.10 \\
\hline Choline chloride (60\%) & 0.05 & 0.05 & 0.05 \\
\hline L-Valine & 0.03 & 0.02 & 0.02 \\
\hline Xylanase $^{c}$ & 0.02 & 0.02 & 0.02 \\
\hline $\mathrm{TiO}_{2}$ & 0.00 & 0.05 & 0.00 \\
\hline \multicolumn{4}{|l|}{ Nutrient composition (\%) ${ }^{d}$} \\
\hline ME (kcal/kg) & 2,940 & 3,000 & 3,033 \\
\hline Crude protein & 23.2 & 22.0 & 20.4 \\
\hline Ether extract & 4.96 & 5.34 & 5.93 \\
\hline Calcium & 1.27 & 1.12 & 0.77 \\
\hline Phosphorus & 0.73 & 0.67 & 0.84 \\
\hline Ash & 6.70 & 6.10 & 4.70 \\
\hline
\end{tabular}

a,b Provided per kilogramme of diet: vitamins, minerals and digestible AA according to Aviagen Nutrient specifications (Aviagen, 2019).

${ }^{c}$ Ronozyme WX, DSM Nutritional Products Ltd.

dMeans day.

according to the nutritional specifications/requirements of the Ross 308 broiler breeders (Aviagen, 2019) apart from the level of vitD 3 added (Table 1 ). The level of vitD 3 was mixed as an additional supplement to the standard basal diet, which was first manufactured without vitD $\mathrm{D}_{3}$, then added vitD $\mathrm{D}_{3}$ to produce premixes to give 4,000 vitD $_{3}$ in treatment.

\section{Data Collection, Experimental Procedure, and Sampling}

All chicks were checked for health and mortality twice a day; the birds that died during the experimental period were weighed and sent to the pathology laboratory for a necropsy. Some measurements were taken as described below.

\section{Growth Performance}

The body weight gain (BWG) was measured by taking individual body weight at $0,10,17,24,31$, and $38 \mathrm{~d}$ of age; feed intake (FI) was measured by subtracting feed refused from feed offered on a weekly basis. From the data obtained, FCR was estimated by dividing the FI with BWG at the end of starter (10 d), grower (24 d), and finisher periods ( $38 \mathrm{~d}$ ) for each group of birds in a pen.

\section{Social Isolation Stress}

Social isolation stress was tested on broilers to determine the stress responses of broilers treated with dietary vitD $\mathrm{D}_{3}$ or UVB light. The isolated birds were subjected to regular sessions of social isolation by putting in a plastic/storage box for 15-min periods over the course of 3 days a week for 2 weeks starting from day 10 (90 min total exposure) with an inter-treatment interval of $48 \mathrm{~h}$. Fifteen minutes of isolation was selected as this time period, or less, has been found to be associated with pessimisticlike behaviour in cognitive bias tests (Salmeto et al., 2011), elevated corticosterone (Sufka et al., 2006) and interleukin-6 and has been pharmacologically validated using anxiolitics in chicks (Warnick et al., 2009). To isolate a bird, it was gently captured or taken out from the home pen and put in an isolation box with dimensions $(1 \times \mathrm{w} \times \mathrm{h}: 54 \times 41 \times 46 \mathrm{~cm})$ where the captured birds had vocal contact but limited sight of other birds. The isolated birds had no physical contact with other birds under isolation. Thus, the birds were exposed to a combination of capturing, handling, social isolation, feed and water deprivation, and sawdust litter at the bottom of the box. The duration of capturing four birds and putting those in a box was $\sim 2 \mathrm{~min}$ and the birds remained in the box for $15 \mathrm{~min}$ before being returned to their home pens. Conversely, the control birds remained in their home pens during the test periods; they were never captured, handled, or out of visual and vocal contact with others. Both groups experienced regular husbandry activities (i.e., the presence of humans changing food, water and bedding material) in their home pen (Goerlich et al., 2012; Weldon et al., 2016).

\section{Blood Sampling for Serum 25-OH- $\mathrm{D}_{3}$ and Chicken CORT Levels}

At 24 and 42 days of age, selected birds (two birds per pen; $n$ $=64$ ) were individually weighed and subsequently euthanized using a schedule 1 procedure with a lethal injection of sodium barbiturate (Euthatal, Merial Harlow, United Kingdom) via the wing vein. The blood samples were used for measuring serum levels of $25-\mathrm{OH}-\mathrm{D}_{3}$ and CORT to determine the physiological effects of social isolation stress and the role of dietary vit $\mathrm{D}_{3}$ and UVB light to alleviate stress. Blood was sampled via the heart cavity using a $5 \mathrm{ml}$ syringe and placed in $5 \mathrm{ml}$ serum tubes (red-topped tubes) with serum clot activator (BD Vacutainer, SST II Advance Plus Blood Collection Tubes-BD, Plymouth, United-Kingdom). The blood samples were allowed to clot by standing undisturbed for $1.5 \mathrm{~h}$ at room temperature; $0.5 \mathrm{ml}$ supernatant aliquoted serum was transferred in two replicates using a pipette following centrifugation for $15 \mathrm{~min}$ at $1,500 \times$ $\mathrm{g}$ in Eppendorf tubes and stored at $-80^{\circ} \mathrm{C}$ before laboratory analyses. Corticosterone high sensitivity enzyme immunoassay was used for the quantitative determination of chicken CORT levels where the calibrators, controls and samples were pretreated by adding assay buffer and incubating at $80^{\circ} \mathrm{C}$ for $30 \mathrm{~min}$ according to the methods described by Bacarese-Hamilton et al. (1992). The chemiluminescent immunoassay (CLIA) method was used for $25-\mathrm{OH}-\mathrm{D}_{3}$ as described by Chen et al. (2020). 
A
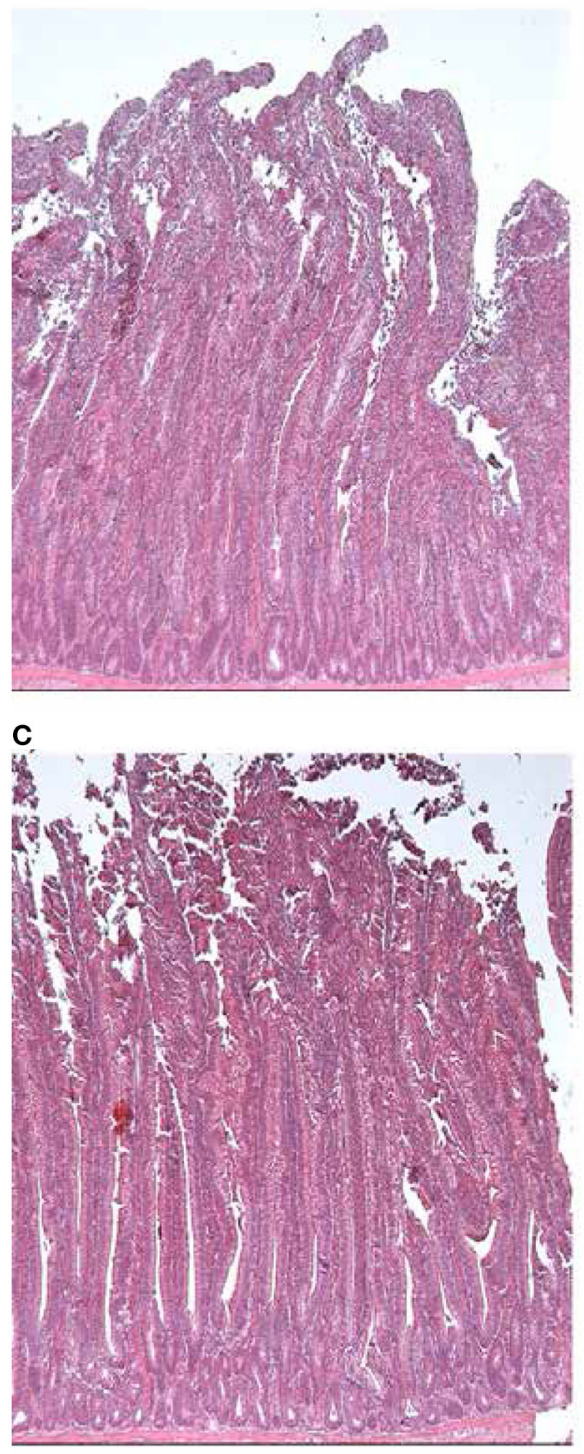

B

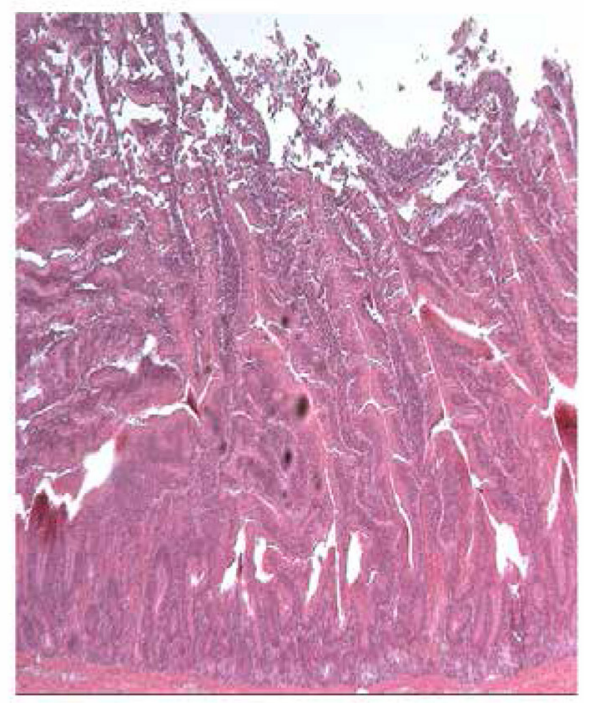

D

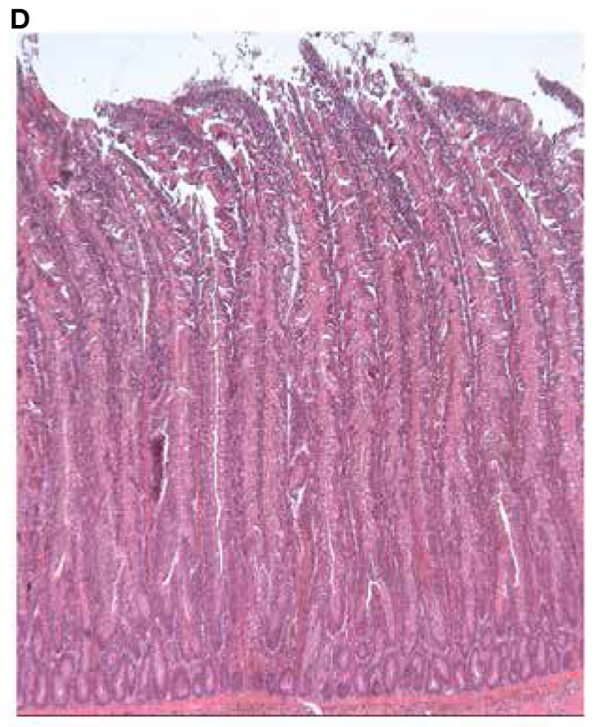

FIGURE 2 | Histological representations of the duodenal villi and crypt depth of broiler chickens from the (A) HD non-isolated, (B) UVB non-isolated, (C) HD isolated, and (D) UVB isolated treatment group.

\section{Gait Score}

GS was performed when the birds were 23 and 37 days of age. Two birds per pen were randomly selected and individually assessed for their walking capacity using the 0-5 gait scoring system (Garner et al., 2002). A score of 0 represents a perfect gait, and a score of 5 represents an inability to stand. Briefly, gait score 0 (GS 0) describes a bird with normal and perfect gait; GS 1 birds have an imperfect but unclear gait defect; GS 2 birds have an identifiable gait defect; GS 3 birds have an obvious gait abnormality; GS 4 birds have a severe gait defect, only walking when motivated; GS 5 birds cannot stand and cannot walk. The wing tag of each bird was noted, and the bird was subsequently assessed by two experienced and independent observers who caught and observed the birds. The score was then discussed between the observers, and the bird was possibly re-assessed until an agreement between the observers was reached.

\section{Feather Score}

FS was performed when the birds were 22 (four birds per pen; $n=128$ ) and $35 \mathrm{~d}$ of age. Broilers were randomly chosen and individually assessed for their feather development and cover, using the two scoring systems, viz the Royal Society for the Prevention of Cruelty to Animals (RSPCA) FS index: lower number $=$ more covered $($ RSPCA, 2017) and a percentage cover score (\% CV) system (higher \% = more covered) (Bilcik and Keeling, 1999; LaBrash and Scheideler, 2005). The RSPCA index is a five-point scale of $0-2$, assigning birds a score of feather coverage from "full and even over body and wings" to "bare on 


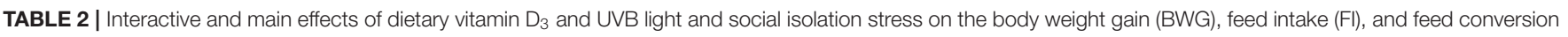
ratio (FCR) of broilers over the starter (day 0-10), grower (day 0-24), and finisher period (day 0-38) and serum 25-OH-D levels at 24 and 42 days of age.

\begin{tabular}{|c|c|c|c|c|c|c|c|c|c|c|c|}
\hline \multirow[b]{2}{*}{ Treatments } & \multicolumn{3}{|c|}{ BWG (g) } & \multicolumn{3}{|c|}{$\mathbf{F I}(g)$} & \multicolumn{3}{|c|}{ FCR (g:g) } & \multicolumn{2}{|c|}{$\begin{array}{l}25-\mathrm{OH}-\mathrm{D}_{3} \\
\text { levels (nmol/I) }\end{array}$} \\
\hline & $0-10$ & $0-24$ & $0-38$ & $0-10$ & $0-24$ & $0-38$ & $0-10$ & $0-24$ & $0-38$ & 24 & 42 \\
\hline Commercial standard & 321 & 1,125 & 2,527 & 304 & 1,542 & 3,872 & 0.95 & 1.26 & 1.53 & & \\
\hline HD Control & $268.52^{b}$ & $1,286.8^{a}$ & $2,719 \cdot 1^{b}$ & 302.63 & $1,634.7^{a}$ & $3,976.7^{a, b}$ & 1.13 & $1.27^{\mathrm{b}}$ & $1.46^{a, b}$ & 131.88 & $144.63^{a}$ \\
\hline HD Isolated & $282.40^{a}$ & $1,324.8^{a}$ & $2,942.6^{a}$ & 306.52 & $1,673.7^{a}$ & $4,203.7^{a}$ & 1.09 & $1.26^{b}$ & $1.43^{b}$ & 96.25 & $123.63^{\mathrm{ab}}$ \\
\hline UVB Control & $282.85^{a}$ & $1,150 \cdot 1^{b}$ & $2,523 \cdot 6^{b, c}$ & 316.65 & $1,626.7^{a, b}$ & $3,787.2^{b, c}$ & 1.12 & $1.42^{\mathrm{a}}$ & $1.50^{\mathrm{a}}$ & 82.63 & $63.88^{b}$ \\
\hline UVB Isolated & $290.18^{a}$ & $1,118.2^{b}$ & $2,419.8^{c}$ & 313.42 & $1,492.5^{b}$ & $3,596.7^{c}$ & 1.08 & $1.34^{a, b}$ & $1.49^{a, b}$ & 95.25 & $104.88^{a, b}$ \\
\hline SEM & 3.532 & 23.089 & 76.213 & 7.714 & 47.251 & 122.491 & 0.029 & 0.034 & 0.056 & 16.092 & 19.784 \\
\hline$P$-value & 0.3623 & 0.1414 & 0.0406 & 0.6478 & 0.0775 & 0.0994 & 0.9739 & 0.2922 & 0.6845 & 0.2082 & 0.1922 \\
\hline$H D$ & $275.46^{b}$ & $1,305.8^{a}$ & $2,830.9^{a}$ & 304.57 & $1,654.2$ & $4,090.2^{a}$ & 1.12 & $1.27^{\mathrm{b}}$ & $1.44^{\mathrm{b}}$ & 114.06 & 134.13 \\
\hline UVB & $286.52^{a}$ & $1,134.1^{b}$ & $2,471.7^{b}$ & 315.03 & $1,559.6$ & $3,692.0^{b}$ & 1.10 & $1.38^{a}$ & $1.50^{\mathrm{a}}$ & 88.94 & 84.38 \\
\hline SEM & 2.497 & 16.326 & 53.891 & 5.455 & 33.411 & 86.614 & 0.020 & 0.024 & 0.017 & 11.379 & 13.990 \\
\hline$P$-value & 0.0041 & 0.0001 & 0.0001 & 0.1860 & 0.0550 & 0.0030 & 0.8626 & 0.0035 & 0.0361 & 0.1935 & 0.0657 \\
\hline Control & $275.68^{b}$ & $1,218.4$ & $2,621.3$ & 309.64 & 1,630.7 & $3,881.9$ & 1.12 & 1.34 & 1.48 & 107.25 & 104.25 \\
\hline Isolated & $286.29^{a}$ & $1,221.5$ & $2,681.2$ & 309.97 & 1,583.1 & $3,900.2$ & 1.08 & 1.30 & 1.46 & 95.75 & 114.25 \\
\hline SEM & 2.497 & 16.326 & 53.891 & 5.455 & 33.411 & 86.614 & 0.020 & 0.024 & 0.017 & 11.379 & 13.990 \\
\hline$P$-value & 0.0056 & 0.8938 & 0.4383 & 0.9658 & 0.3224 & 0.8827 & 0.1701 & 0.2138 & 0.4233 & 0.5143 & 0.6398 \\
\hline
\end{tabular}

$H D, 4,000 \mathrm{IU} / \mathrm{kg}$ level of $D_{3}$ only; UVB, UVB light only.

Bold indicates $P$-values $<0.05$.

Commercial standards for the breed are provided based on (Ross 308 Performance Objectives, 2019).

$a, b, c$ Mean values in the same column bearing the same superscript are similar while not sharing a common superscript are statistically different ( $P<0.05)$.

SEM, Standard error of the mean; NB, Broilers were not isolated during the starter period (days 0-10).

the body and patchy on the wings." Briefly, feather score 0 (FS 0) describes a bird with full feather cover; FS 0.5 birds have a slight patchy feather cover; FS 1 birds have patchy to bare feather cover; an FS 1.5 bird have a patchy to bare feather cover on the sides of the body with a light covering on the back; FS 2 birds have a bare feather on body and wings. The $\% \mathrm{CV}$ assigns a percentage cover to four areas of the chicken: (i) head; (ii) combined back and wing region; (iii) front of the neck and lower body in front of the legs; (iv) lower rear body behind the legs. For each region, there was a score of $0-9$, where, $0=0-9 \%$ adult feathers, $1=10-19 \%, 2=$ $20-29 \%, 3=30-39 \%, 4=40-49 \%, 5=50-59 \%, 6=60-69 \%, 7$ $=70-79 \%, 8=80-89 \%, 9=90-100 \%$.

\section{GIT Components Weights}

At 42 days of age, two birds per pen were humanely killed and cut opened to collect and measure the full weight of their heart, liver, pancreas, proventriculus, and gizzard ( $\mathrm{Pr}+\mathrm{Gizz})$, spleen, small intestine (Small I) and bursa of Fabricus. Organ weights were expressed as a percentage of body weight by dividing organ weight with body weight and multiplying by 100 .

\section{Gut Histomorphology}

The histomorphology of the small intestine (duodenum, jejunum and ileum) was performed at 42 days of age, selected birds (I bird per pen) were dissected and the abdomen was cut open through a midline incision to gently remove the small intestine of each bird. Then the small segment of about $3 \mathrm{~cm}$ of mid-duodenum (from the gizzard to pancreatic and bile duct), jejunum (from the bile duct to Meckel's diverticulum) and ileum (from the Meckel's diverticulum to ileocaecacolonic junction were immediately located and excised (Samanya and Yamauchi, 2002). Excised intestinal tissues were fixed in 10\% neutral buffered formalin (Merck Life Science Limited New Road, The Old Brickyard Gillingham Dorset, SP8 4XT, UK) filled pots (Caruso et al., 2012; Sabet Sarvestani et al., 2015). After 3 days, the tissue samples were rinsed to remove the formalin and fixed in ethanol (analytical reagent) solution at 70\%. The fixed tissue samples were then transported to the Central BioBank, Faculty of Medicine, Newcastle University. They were further processed, trimmed to eliminate the torn edges, and remained for further $24 \mathrm{~h}$ in the fixing solution. The tissues were then dehydrated with increasing concentrations of ethyl alcohol (70, 90,96 , and $100 \%$ ), cleared in xylene and embedded in paraffin. The paraffin blocks were then cut using a microtome $(\mu \mathrm{m})$ into $4-\mu \mathrm{m}$-thick discontinuous paraffin-embedded sections per broiler tissue sample that were stained using haematoxylin and eosin (H\&E) (for standard histological evaluation). In order to analyse histomorphometric features of each segment, villus height (VH), crypt depth (CD), villus height to crypt depth ratio (VH:CD) were measured by examining slides, photographing digital images and capturing randomly selected 3 representative fields using image capture and analysis system (Leica Biosystems Image scope software; Leica application suite version 3.4). $\mathrm{VH}$ and $\mathrm{CD}$ were measured in duodenum, jejunum and ileum sections. $\mathrm{VH}$ was measured as the distance from the apex of the villus to the junction of the villus, whereas CD was measured from the base of the villus up to the cryptvilli transition region/mucosa. The VH:CD was determined by 
TABLE 3 | Interactive and main effects of dietary vitamin $D_{3}$ and UVB light and social isolation on the GIT component weights (g) relative to live weight of broilers aged $42 \mathrm{~d}$.

\begin{tabular}{|c|c|c|c|c|c|c|c|}
\hline Treatments & Pr.+Gizz. & Small I. & Pancreas & Liver & Heart & Spleen & Bursa \\
\hline HD control & $2.11^{a, b}$ & $4.16^{b}$ & 0.19 & $2.49^{b}$ & $0.55^{\mathrm{b}}$ & $0.13^{b}$ & $0.15^{\mathrm{b}}$ \\
\hline HD isolated & $1.92^{b}$ & $4.66^{a}$ & 0.30 & $2.71^{a}$ & $0.64^{a}$ & $0.15^{a}$ & $0.17^{\mathrm{a}, \mathrm{b}}$ \\
\hline UVB control & $2.37^{a}$ & $4.33^{a, b}$ & 0.20 & $2.42^{\mathrm{b}}$ & $0.59^{a, b}$ & $0.14^{a, b}$ & $0.22^{a, b}$ \\
\hline UVB isolated & $2.38^{a}$ & $4.56^{a, b}$ & 0.21 & $2.61^{a, b}$ & $0.64^{a}$ & $0.15^{a, b}$ & $0.29^{a}$ \\
\hline SEM & 0.100 & 0.176 & 0.051 & 0.071 & 0.213 & 0.007 & 0.049 \\
\hline$P$-value & 0.325 & 0.457 & 0.298 & 0.823 & 0.435 & 0.353 & 0.611 \\
\hline$H D$ & $2.01^{b}$ & 4.41 & 0.25 & 2.60 & 0.60 & 0.14 & 0.16 \\
\hline UVB & $2.38^{a}$ & 4.44 & 0.20 & 2.52 & 0.61 & 0.15 & 0.26 \\
\hline SEM & 0.071 & 0.125 & 0.036 & 0.051 & 0.015 & 0.005 & 0.035 \\
\hline$P$-value & 0.001 & 0.845 & 0.393 & 0.229 & 0.396 & 0.823 & 0.058 \\
\hline Control & 2.24 & $4.24^{b}$ & 0.19 & $2.46^{b}$ & $0.57^{b}$ & 0.14 & 0.19 \\
\hline Isolated & 2.15 & $4.61^{a}$ & 0.25 & $2.66^{a}$ & $0.64^{a}$ & 0.15 & 0.23 \\
\hline SEM & 0.071 & 0.125 & 0.036 & 0.051 & 0.015 & 0.005 & 0.348 \\
\hline$P$-value & 0.415 & 0.041 & 0.228 & 0.006 & 0.002 & 0.055 & 0.371 \\
\hline
\end{tabular}

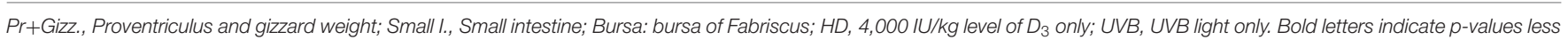
than 0.05 .

a,b Means in each column bearing different superscripts are significantly different $(P<0.05)$.

SEM, Standard error of the mean.

TABLE 4 | Effect of dietary vitamin $D_{3}$ and UVB light and social isolation stress on intestinal tissue histology analysis of broilers chickens at 42 days of age.

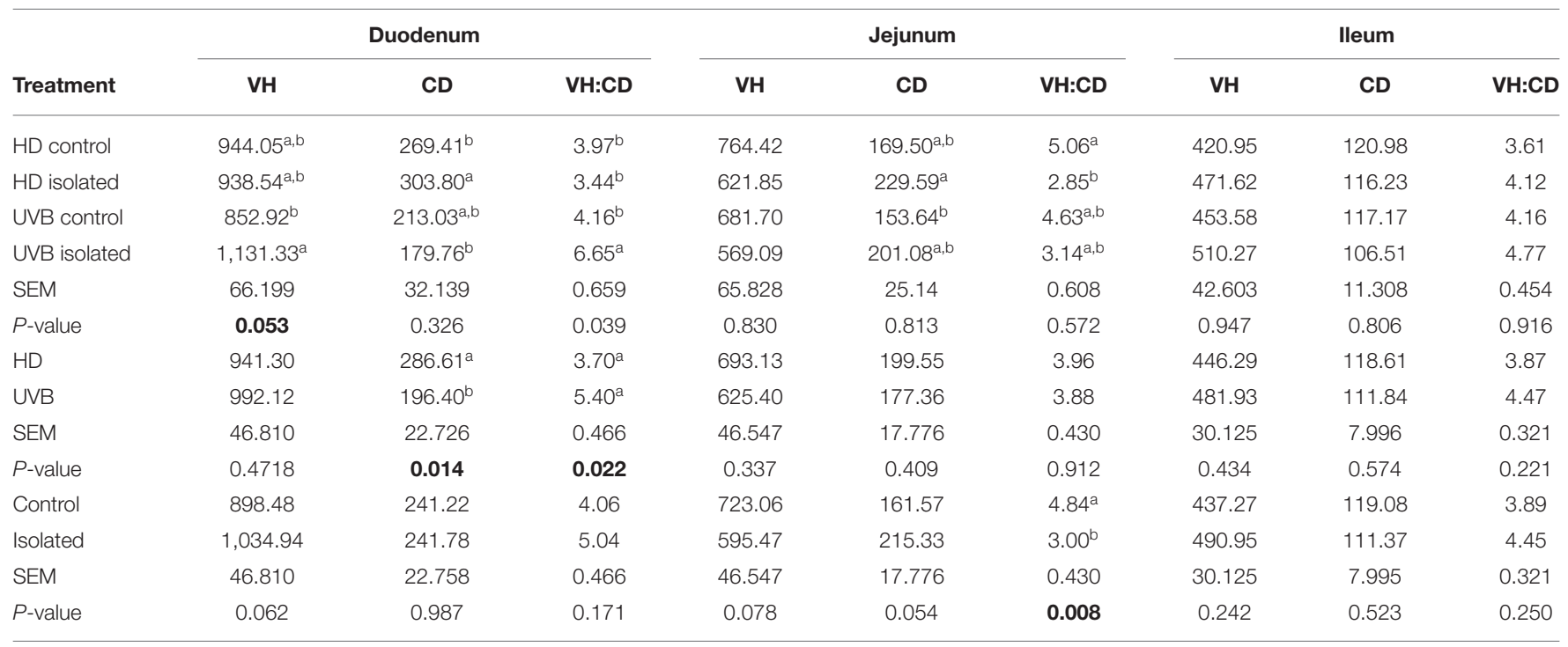

$H D, 4,000$ IU/kg level of $D_{3}$ only; UVB, UVB light; VH, Villus height; $C D$, Crypt depth; VH:CD, The ratio of villus height to crypt depth. Bold letters indicate $p$-values less than 0.05 .

${ }_{a, b}$ Mean values in the same column bearing the same superscript are similar while not sharing a common superscript are statistically different ( $\left.P<0.05\right)$.

SEM, Standard error of the mean.

dividing the VH by the CD (Brudnicki et al., 2017; Prakatur et al., 2019). The criterion for villus selection was based on the presence of intact lamina propria. $\mathrm{VH}$ and $\mathrm{CD}$ were measured at $10 \times$ the objective magnification. The measurements were taken from 10 villi heights and crypt depths of the three representative fields per sample for each bird and expressed as the average villi height and crypt depth for each bird in a treatment group (Brudnicki et al., 2017). The histological representations of the broiler chickens duodenum from the treatments are shown in Figures 2A-D.

\section{Experimental Design and Statistical Analysis}

The experiment was a $2 \times 2$ factorial design. Data collected on growth performance (pen BW, FI and FCR for the starter, grower and finisher stages), FS, GS, 25-OH-D 3 levels, GIT components and gut histology of broiler chickens were statistically analysed using the General Linear Model (GLM) procedure of the statistical analysis of variance software 9.4 programs (SAS Institute Inc., 2012) while the CORT levels were 

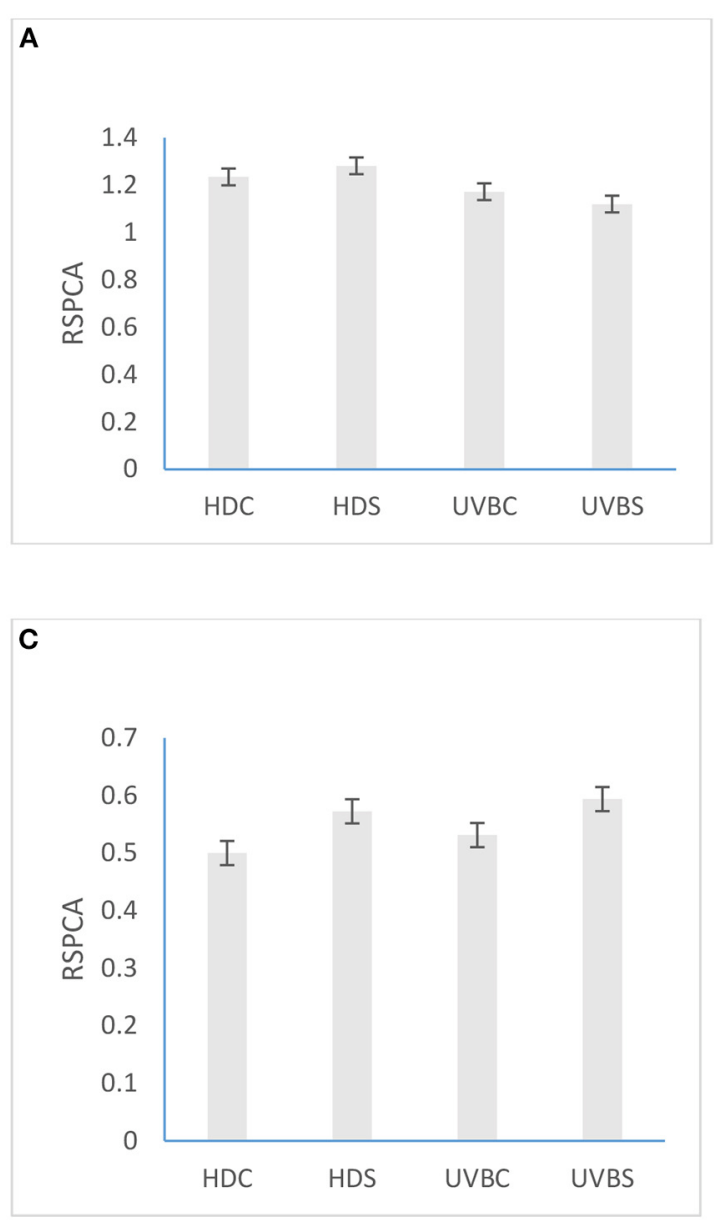
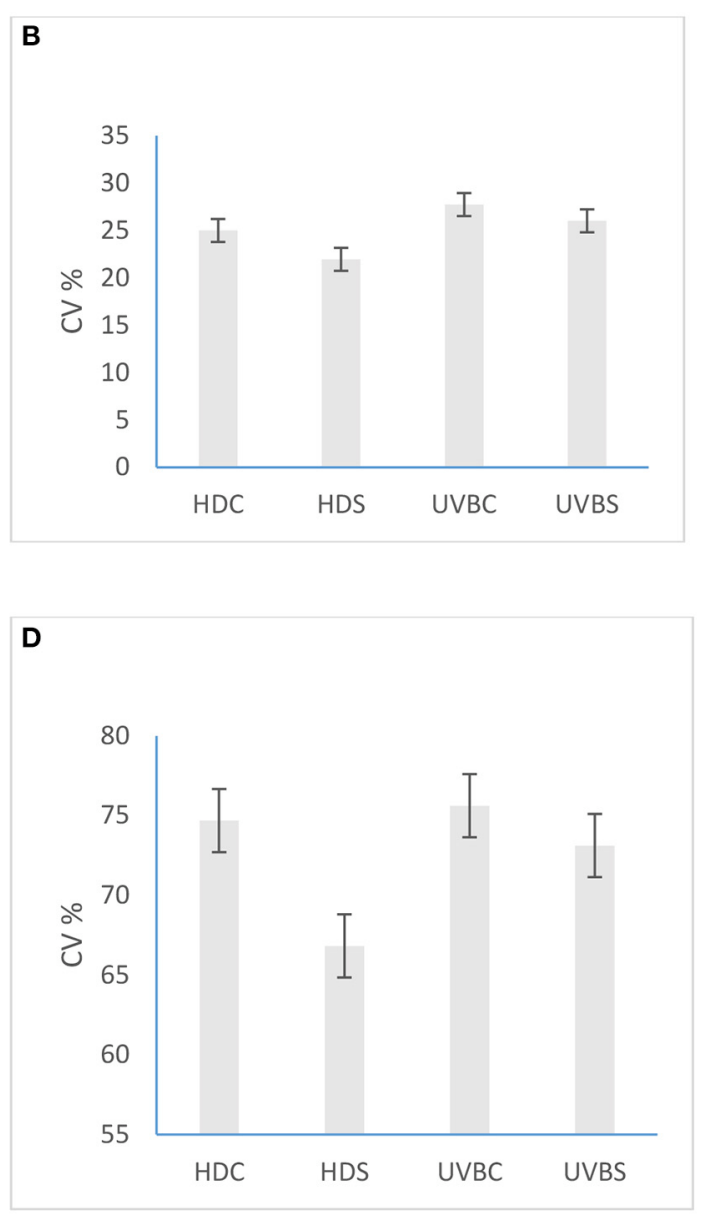

FIGURE 3 | Effects of dietary vitamin $D_{3}$ and UVB light wavelength in the control and isolated birds on (A) RSPCA of broiler chickens at 23 days; (B) Cover scores of broiler chickens at 23 days; (C) RSPCA of broiler chickens at 35 days; (D) Cover scores of broiler chickens at 35 days of age.

compared on the control and isolated birds to determine the impact of isolation. A non-parametric test, a Mann Whitney $U$ and Wilcoxon rank-sum test with continuity correction were used to assess the normality of residuals. The pen was the experimental unit for all the data collected. Significance was designated as $P \leq 0.05$ (5\% level of probability). All values are expressed as model-predicted least-square means with the standard error of the mean (SEM). In this study, multiple statistical comparisons were made, and it is worth stating that testing for multiple corrections was not applied. If we had used an improved Bonferroni correction for multiple testing across all the statistical tests, $P$-values $>0.002$ would not have been significant. This would have resulted in observing the main effects of the source of $\mathrm{vitD}_{3}$ on body weight and proventriculus and gizzard weight and the effects of social isolation on heart weight and feathering. For the current study with a range of different indicators, such an approach was deemed to be too conservative, but this information was provided to allow the reader to draw their conclusions.

\section{RESULTS}

The mean values for the analysis of the production characteristics data (FI, BWG, and FCR) of broiler chickens challenged with social isolation stress during the $0-38$ days are shown in Table 2. There was a treatment interaction effect $(P=0.0406)$ on the BWG of the birds; the HD isolated group tended to be highest at 38 days of age compared to other treatments. HD and UVB differed for their effect on BWG, FI and FCR of broilers. UVB had higher BWG $(P=0.0041)$ over the starter phase, lower BWG (Glm: $\left.F_{1,30}=55.28 ; P=0.0001\right)$ over the grower, and lower BWG over the finisher phase (Glm: $F=22.21 ; P=0.0001)$. FI tended to be lower (Glm: $\left.F_{1,30}=4.01 ; P=0.0550\right)$ in UVB birds at 24 days and lower (Glm: $\left.F_{1,30}=10.57 ; P=0.0030\right)$ FI at 38 days of age. FCR differed $(P<0.05)$ with HD birds having lower values and improved growth than UVB birds at 24 and 38 days, while no effect $(P>0.05)$ of social isolation stress was observed on BWG at 24 and 38 days, FI and FCR. The serum levels of $25-\mathrm{OH}-\mathrm{D}_{3}$ were unaffected $(P>0.05)$ by the treatments at 24 and 42 days of age, and no treatment interaction was observed (Table 2). 


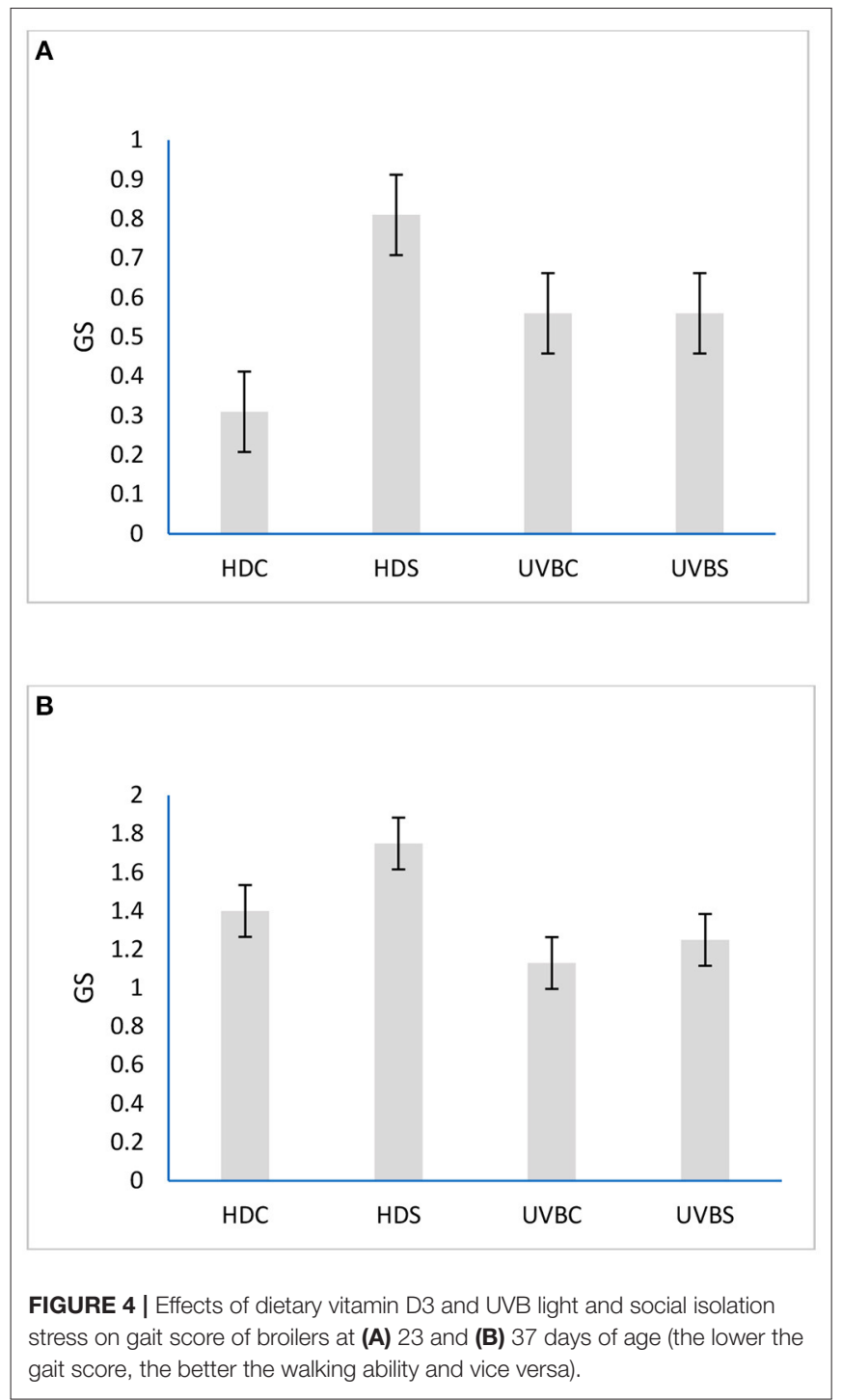

The UVB birds had heavier proventriculus plus gizzard $(P=$ $0.001)$ and heavier bursa $(P=0.058)$ compared to the HD birds, while the isolated birds had heavier $(P<0.05)$ small intestine, liver, and heart weights than the control birds at 42 days of age. No interaction between treatments was observed (Table 3).

UVB treated birds demonstrated reduced CD $(P=0.014)$ and increased VH:CD $(P=0.022)$ at the duodenum while control birds had increased VH:CD $(P=0.008)$ at the jejunum. Treatment interaction effect $(P<0.05)$ was observed at the $\mathrm{VH}$ and $\mathrm{VH}: \mathrm{CD}$ in the duodenum of broilers (Table 4 ).

Figure 3 presents the mean values of RSCPA and CV\% for broilers in HD control and isolated vs. UVB control and isolated at 23 ( 1.23 and 1.28 vs. 1.17 and $1.12, P=1.000$, Figure $3 \mathrm{~A}$ ), (25 and 21.95 vs. 27.73 and 26.02, $P=0.671$, Figure $3 B$ ) and 35 days old ( 0.50 and 0.57 vs. 0.53 and $0.59, P=0.955$, Figure $3 \mathrm{C}$ ); (74.69 and 66.83 vs. 75.63 and 73.13, $P=0.111$, Figure 3D), respectively. The main effects of treatment showed that UVB birds had better feathering/CV\% at 23 (GLM: $F_{1,126}=4.72 ; P$
$=0.0316)$ and 35 (GLM: $\left.F_{1,61}=4.45 ; P=0.0329\right)$ days of age while isolation stress reduced feathering/CV\% (GLM: $F_{1,61}$ $=9.79 ; P=0.0027$ ) of broilers at 35 days of age compared to their counterparts.

The mean GS of broilers in HD control and isolated vs. UVB control and isolated were ( 0.31 and 0.81 vs. 1.13 and $1.25, P=$ 0.071 , Figure $4 \mathrm{~A})$ at 24 and $(1.40$ and 1.75 vs. 1.13 and $1.25, P$ $=0.461$, Figure $4 B$ ) at 35 days old, respectively. UVB birds had better (GLM: $\left.F_{1,61}=6.62 ; P=0.0125\right)$ GS at 37 days of age compared to their counterparts (Figure 4).

The serum levels of CORT of broilers were higher in the isolated chickens than the control chickens $(W=71.5, \mathrm{df}=3$, $P=0.0347)$ at 42 days of age (Figure 5).

\section{DISCUSSION}

This study was designed to understand the best strategy for the provision of vitD 3 to commercial broilers reared indoors by providing either dietary vitD 3 at $4,000 \mathrm{IU} / \mathrm{kg}$ or UVB light to determine which was capable of improving physiological, metabolic, and welfare indicators of broiler chickens challenged with social isolation stress. To the best of the knowledge, this is the first study to compare the effects of dietary vitD $\mathrm{D}_{3}$ and UVB light in broilers challenged with a stressor, in this case, short periods of repeated social isolation. Despite relatively short durations of social isolation, differences in CORT measured at the end of the trial (42 days) indicated this challenge was a stressor for broiler chickens, along with differences in organ weight. Both dietary vit $\mathrm{D}_{3}$ and UVB light resulted in comparable levels of serum $25-\mathrm{OH}-\mathrm{D}_{3}$, the major circulating form and principal metabolite of vitD 3 . Broiler chickens challenged with this stressor while receiving a UVB light source of vitD $\mathrm{D}_{3}$ gained less weight and had a lower feed intake but had comparable feed conversion ratios. There were no interactive effects on welfare measures of gait score and feather score. Thus, the results do not support the hypothesis that UVB supplementation would increase production parameters such as FCR and improve broiler health and welfare for chickens under stress. There were some differences between the main effects of dietary vitD $\mathrm{D}_{3}$ and UVB light and control vs. isolation groups which warrant further discussion, as does the interpretation of the differences in body weight observed between the treatments.

FCR was affected by the main effects of treatments, with lower (improved) FCR under dietary vitD $\mathrm{D}_{3}$ supplemented condition, but both compared well with the target FCR of 1.5 for Ross 308. This study hypothesised that UVB light would have a positive effect on FCR due to the super-visual eye system of poultry, which allows the discrimination of a broad area of the visible light spectrum (Akyüz and Onbasilar, 2018) and could facilitate feeding. Light is one of the most important environmental parameters in poultry production, not only providing illumination for the birds but also regulating many physiological processes such as vision which is important for facilitating feeding (Olanrewaju et al., 2016; Rault et al., 2016; Soliman and El-Sabrout, 2020). Birds gained more weight early on (during the starter phase days 0-10) when under UVB light, 


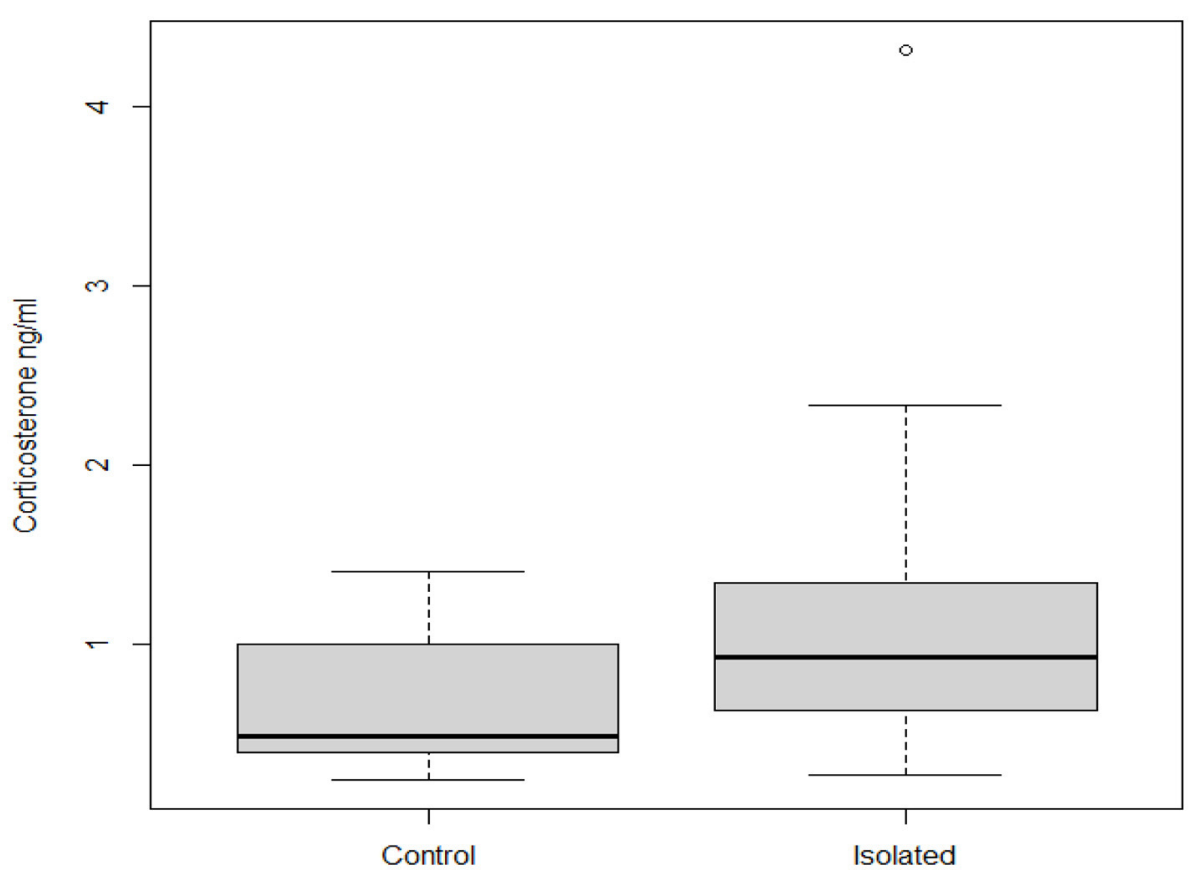

FIGURE 5 | Effect of isolation treatment on serum corticosterone levels $(\mathrm{ng} / \mathrm{mll}$ ) of broiler chickens at 42 days of age after a repeated challenge of $15 \mathrm{~min}$ of social isolation.

so it may be that UVB light helped to stimulate early feeding but does not seem to outperform dietary vit $\mathrm{D}_{3}$ by the time birds reach slaughter age.

No differences in FCR were observed in broiler chickens challenged with the 2-week social isolation stress period. Inconsistent with the findings, previous studies reported production performance (Goerlich et al., 2012), where chickens that had experienced early isolation stress gained more weight later in life and upregulation of early growth response 1 gene (EGR1), though the study did not provide comparisons like treatments in this study. In this study, there was an interaction effect on weight, with the UVB light treated chickens that had experienced isolation stress being lighter than the chickens which received dietary supplementation and experienced the isolation stress. This is interesting because, commercially, this is a less desirable outcome; it does suggest some potential buffering effect of UVB lighting in the effects of corticosterone, at least on the impact on weight. The two studies differ in terms of the length and number of repeats of the isolation in the current study, which could explain the lack of a main effect of the isolation treatment. It would be interesting to further explore the feeding behaviour, weight gain and gene regulation in stressed chickens with and without UVB supplementation.

Lupien et al. (2009) demonstrated that the rate of effect of stress (amount and intensity of changes) could differ according to the intensity and duration of stress. Isolated birds may have engaged in compensatory feeding by increasing their feed intake once they returned to the pens from isolation since food was provided ad-libitum except during the isolation.
This may indicate a response to a sudden need to adapt to fluctuating/challenging environments or a need to respond to increased food availability (Lindqvist et al., 2007).

As $25-\mathrm{OH}-\mathrm{D}_{3}$ is the primary circulating form and principal metabolite of $\operatorname{vitD}_{3}$ in blood, its concentration reflects or measures the vitamin $\mathrm{D}$ status of the animal (Browning and Cowieson, 2014). The UVB-treated broilers had similar levels of $25-\mathrm{OH}-\mathrm{D}_{3}$ to $\mathrm{HD}$. Inconsistent with the present findings, previous research (Veleva et al., 2020) reported that the UVB group patients with dementia had lower serum $25-\mathrm{OH}-\mathrm{D}_{3}$ concentration compared to the oral vitamin $\mathrm{D}$ supplemented group. This may be due to species differences or differences in the intensity of the UVB light supplementation.

The GIT is a highly complex and dynamic organ, which plays a critical role in providing the biological environment for nutrient digestion, absorption and immune response (Lan et al., 2005). The broiler's fast growth rate and increased GIT stimulate feed intake (Garcia et al., 2013). The UVB light improved proventriculus plus gizzard organ weight of broilers at 42 days of age compared to the HD birds, indicating a good digestive capacity for nutrient absorption. However, this did not translate to corresponding differences in weight. Previous research (Kokoszynski et al., 2017) has reported that the high proportion of gizzard might indicate a good digestive capacity for nutrient absorption. The increased weight of the bursa (an immune organ) in UVB birds might be related to reduced stress response and better adaptability to stress. The isolated birds had significantly heavier small intestine, heart, and liver weight at 42 
days of age than non-isolated birds but did not translate to the overall weight change.

Histomorphometric analysis is extensively used in gastrointestinal pathophysiology studies, and its functional status is defined by villus height and crypt depth (Laudadio et al., 2012). For instance, an increase in villus height may result in increased villus absorptive area and function, leading to a higher digestive enzyme action and higher transport of nutrients at the villus surface area (Tufarelli et al., 2012). Therefore, an increase in villus height, villus height to crypt depth ratio or decrease in the crypt depth is correlated with an improvement in the digestion and absorption of nutrients (Hou et al., 2013). Reduced CD and increased VH:CD on the duodenum, as demonstrated by the UVB light supplemented birds, indicated a better potential for nutrient absorption. This is the first study that compared dietary vitD $\mathrm{D}_{3}$ and UVB light on the histology of broilers challenged with social isolation stress.

Social relationships are beneficial for humans as well as animals (Smith et al., 2011), especially for those animals that live in groups (flock of chickens). Social isolation could impact homeostatic stability and welfare integrity, leading to dysfunction and detrimental health conditions (Westenbroek et al., 2004; Grippo et al., 2007; Norman et al., 2010; Smith et al., 2011). Veleva et al. (2020) reported that UVB light compared to oral vitamin $\mathrm{D}$ showed no positive and beneficial effects on the wellbeing of nursing home residents with dementia. Still, it was observed that UVB light had a calming effect on the restless/tense behaviour of nursing home residents with dementia (Veleva et al., 2020). It also improved the mood, depressive disorders, and wellbeing of patients indicating a positive effect of UVB light on welfare (Veleva et al., 2018).

Intact feather cover is paramount for movement, flight, skin protection from tissue damage and infections (LaBrash and Scheideler, 2005), thermoregulation, and navigation of the bird within its environment (Bilcik and Keeling, 1999). This makes a non-intact feather cover a problem with potential risk factors. Therefore, feathering acts as an essential social signal or indicator of condition in broiler chickens with potential welfare implications as it can be used to judge an individual's condition (Bulluck et al., 2017; Jovani and Rohwer, 2017). The current study indicated that UVB light improved the feather development and cover of broilers, while isolation stress reduced it. This is the first research to determine the effect of dietary vitD $\mathrm{D}_{3}$ and UVB light source on FS of broilers challenged with social isolation stress.

Poorer walking ability (gait scores) was found in broilers that received dietary rather than light supplementation of vit $\mathrm{D}_{3}$. It is likely that this result is explained by differences in body weight which would be consistent with a wealth of previous studies (Kestin et al., 2001; Sanotra et al., 2001; Kristensen et al., 2006; Caplen et al., 2012; Ogbonna et al., under review) which have indicated that weight influences gait score. Rutten et al. (2002) showed that the broiler's walking ability was enhanced when their body weight was reduced. Caplen et al. (2012) showed that the lame birds walked slower and took shorter and quicker strides than the non-lame broilers, which may be an attempt to minimise discomfort and stress on the bones. Previous reports (Maddocks et al., 2001; Bailie et al., 2013) suggested that the UVB light increased activity and exploratory behaviours in chickens, which in turn can positively improve the bone development and tendons and consequently the walking ability of broiler chickens (Foutz et al., 2007; Moussa et al., 2007).

Serum CORT concentration has been commonly used to assess the stress response of poultry (Bortolotti et al., 2008; Weimer et al., 2018). In the present study, social isolation increased serum CORT levels in broilers. The effects of treatments interaction on serum CORT were not investigated; instead, this data was used to confirm the effects of the social isolation treatment on broilers. The sample size in CORT was not considered large enough to be able to detect interaction effects, although this would be interesting to explore in future research. It has been found that ultraviolet lighting lowered stress in Pekin ducks (House et al., 2020b) and broilers (House et al., 2020a), indicating that ultraviolet light could lower stress susceptibility. Previous studies (Maddocks et al., 2001; Archer and Mench, 2014; Huth and Archer, 2015; Archer, 2019; Sobotik et al., 2019) have also demonstrated poultry stress responses/parameters such as CORT could be affected by light. Therefore, it is an area that needs further exploration to establish the reason behind stress overcoming properties of UVB.

\section{CONCLUSIONS}

The results of this study are mixed but indicate some positive effects of UVB lighting on welfare indicators and the potential to support early life growth. The possibility of UVB buffering impacts of stress still warrants further investigation. Still, the finding that weight gain was lower in the stress and UVB birds could indicate some buffering of corticosterone effects on weight gain. UVB light exposure in commercial broiler production reared indoors, which are vulnerable to stressors, could be a viable way to support health and welfare integrity.

It is recognised that the broiler's social environment may change dramatically, and stress has a detrimental consequence on the health of broilers. Therefore, large sample size explorations to thoroughly investigate the effects of dietary vitD $\mathrm{D}_{3}$ and UVB light, the association of sex differences in the social environment of different species, strains, and breeds of poultry over a prolonged period of isolation are needed.

\section{DATA AVAILABILITY STATEMENT}

The original contributions presented in the study are included in the article/supplementary material, further inquiries can be directed to the corresponding author. 


\section{ETHICS STATEMENT}

The animal study was reviewed and approved by Animal Welfare and Ethical Review Body (AWERB), Newcastle University (AWERB ID: 806).

\section{AUTHOR CONTRIBUTIONS}

This paper arises from the doctoral thesis of $\mathrm{AO}$. $\mathrm{AO}, \mathrm{AC}$, and $\mathrm{LA}$ designed the research,

\section{REFERENCES}

Akyüz, H. Ç., and Onbasilar, E. E. (2018). Light wavelength on different poultry species. World Poult. Sci. 74, 79-88. doi: 10.1017/S0043933917001076

Alm, M., Holm, L., Rauson, R., and Wall, H. (2014). Corticosterone metabolites in laying hen droppings-effects of fiber enrichment, genotype, and daily variations. Poult. Sci. 93, 2198-2207. doi: 10.3382/ps.2014-04193

Arakawa, H. (2003). The effects of isolation rearing on open-field behavior in male rats depend on developmental stages. Dev. Psychobiol. 43, 11-19. doi: $10.1002 /$ dev. 10120

Archer, G. S. (2019). How does red light affect layer production, fear, and stress? Poult. Sci. 98, 3-8. doi: 10.3382/ps/pey302

Archer, G. S., and Mench, J. A. (2014). Natural incubation patterns and the effects of exposing eggs to light at various times during incubation on post-hatch fear and stress responses in broiler (meat) chickens. Appl. Anim. Behav. Sci. 152, 44-51. doi: 10.1016/j.applanim.2013.12.010

Atencio, A., Edwards, H. M., and Pesti, G. (2005). Effects of vitamin D3 dietary supplementation of broiler breeder hens on the performance and bone abnormalities of the progeny. Poult. Sci. 84, 1058-1068. doi: $10.1093 / \mathrm{ps} / 84.7 .1058$

Aviagen (2019). Ross 308 Broiler: Performance Objectives. Midlothian: Aviagen Limited Newbridge. Available online at: http://en.aviagen.com/assets/Tech_ Center/Ross_Broiler/Ross-308-Broiler-PO-2019-EN (accessed September, 2021).

Bacarese-Hamilton, T., Cattini, R., Shandley, C., Howard, C., Palmer, R., and McFarthing, K. (1992). A fully automated enzyme immunoassay for the measurement of cortisol in biological fluids. Eur. J. Clin. Chem. Clin. Biochem. 30, 531-535. doi: $10.1515 / \mathrm{cclm} .1992 .30 .9 .531$

Bailie, C., Ball, M., and O'Connell, N. (2013). Influence of the provision of natural light and straw bales on activity levels and leg health in commercial broiler chickens. Animal 7, 618-626 doi: 10.1017/S1751731112002108

Bilcik, B., and Keeling, L. J. (1999). Changing in feather condition in relation to feather pecking and aggressive behaviour in laying hens. Br. Poult. Sci. 40, 444-451. doi: 10.1080/00071669987188

Bortolotti, G. R., Marchant, T. A., Blas, J., and German, T. (2008). Corticosterone in feathers is a long-term, integrated measure of avian stress physiology. Funct. Ecol. 22, 494-500 doi: 10.1111/j.1365-2435.2008.01387.x

Browning, L. C., and Cowieson, A. J. (2014). Vitamin D fortification of eggs for human health. J. Sci. Food Agric. 94, 1389-1396. doi: 10.1002/jsfa.6425

Brudnicki, A., Brudnicki, W. R., Szymeczko, Bednarczyk, M., Pietruszynska, D., and Kirkillo-Stacewicz, K. (2017). Histo-morphometric adaptation in the small intestine of broiler chicken, after embryonic exposure to a-Galactosides. J. Anim. Plant. Sci. 27, 1075-1082.

Buijs, S., Keeling, L., Rettenbacher, S., Van Poucke, E., and Tuyttens, F. A. (2009). Stocking density effects on broiler welfare: identifying sensitive ranges for different indicators. Poult. Sci. 88, 1536-1543. doi: 10.3382/ps.20 09-00007

Bulluck, L. P., Foster, M. J., Kay, S., Cox, D. E., Viverette, C., and Huber, S. (2017). Feather carotenoid content is correlated with reproductive success and provisioning rate in female Prothonotary Warblers. Auk 134, 229-239. doi: 10.1642/AUK-16-151.1

Caplen, G., Hothersall, B., Murrell, J. C., Nicol, C. J., Waterman-Pearson, A. E., Weeks, C. A., et al. (2012). Kinematic analysis quantifies gait abnormalities performed the research, interpreted the outcome, and wrote the manuscript. AO run the model. All authors contributed to the article and approved the submitted version.

\section{FUNDING}

This research received support from the TETFund of Nigeria for AO and LA was supported by UKRI, BBSRC-funded project $(\mathrm{BB} / \mathrm{T} 001747 / 1)$. associated with lameness in broiler chickens and identifies evolutionary gait differences. PLoS ONE 7:40800. doi: 10.1371/journal.pone.0040800

Caruso, M., Demonte, A., and Neves, V. A. (2012). Histomorphometric study of role of lactoferrin in atrophy of the intestinal mucosa of rats. Health 04, 1362-1370. doi: 10.4236/health.2012.412198

Carvalho, R. R., Palme, R., and da Silva Vasconcellos, A. (2018). An integrated analysis of social stress in laying hens: The interaction between physiology, behaviour, and hierarchy. Behav. Proces. 149, 43-51 doi: 10.1016/j.beproc.2018.01.016

Chauke, M., Malisch, J. L., Robinson, C., de Jong, T. R., and Saltzman, W. (2011). Effects of reproductive status on behavioral and endocrine responses to acute stress in a biparental rodent, the California mouse (Peromyscus californicus). Horm. Behav. 60, 128-138. doi: 10.1016/j.yhbeh.2011.04.002

Chen, X., Sun, S., Liu, Q., Ren, F., Bai, Z., and Wang, C. (2020). A rapid chemiluminescence immunoassay for total vitamin $\mathrm{D}$ status assessment in fingertip blood. Clin. Lab. 66:34. doi: 10.7754/Clin.Lab.2020.191034

Chou, S., Chung, T., and Yu, B. (2009). Effects of supplemental 25hydroxycholecalciferol on growth performance, small intestinal morphology, and immune response of broiler chickens. Poult. Sci. 88, 2333-2341. doi: $10.3382 /$ ps.2009-00283

Decuypere, E., Bruggeman, V., Everaert, N., Li, Y., Boonen, R., DeTavernier, J., et al. (2010). The broiler breeder paradox: ethical, genetic and physiological perspectives, and suggestions for solutions. Br. Poult. Sci. 51, 569-579. doi: 10.1080/00071668.2010.519121

Deep, A., Schwean-Lardner, K., Crowe, T. G., Fancher, B. I., and Classen, H. L. (2010). Effect of light intensity on broiler production, processing characteristics, and welfare. Poult. Sci. 89, 2326-2333. doi: 10.3382/ps.2010-00964

Duarte, I., Rotter, A., Malvestiti, A., and Silva, M. (2009). The role of glass as a barrier against the transmission of ultraviolet radiation: an experimental study. Photodermatol. Photoimmunol. Photomed. 25, 181-184. doi: 10.1111/j.1600-0781.2009.00434.x

Edwards, H. M. (2003). Effects of uv irradiation of very young chickens on growth and bone development. Br. J. Nutr. 90:151-160. doi: 10.1079/BJN2003860

Foutz, T. L., Griffin, A. K., Halper, J. T., and Rowland, G. (2007). Effects of activity on avian gastrocnemius tendon. Poult. Sci. 86, 211-218. doi: $10.1093 / \mathrm{ps} / 86.2 .211$

Frazer, A. F., and Broom, D. M. (1990). Farm Animal Behaviour and Welfare. London: Baillier Tindall.

Garcia, A. F. Q. M., Murakami, A. E., do Amaral Duarte, C. R., Rojas, I. C. O., Picoli, K. P., and Puzotti, M. M. (2013). Use of vitamin D3 and its metabolites in broiler chicken feed on performance, bone parameters and meat quality. Asian Aust. J. Anim. Sci. 26, 408-415. doi: 10.5713/ajas.2012.12455

Garner, J. P., Falcone, C., Wakenell, P., Martin, M., and Mench, J. A. (2002). Reliability and validity of a modified gait scoring system and its use in assessing tibial dyschondroplasia in broilers. Br. Poult. Sci. 43, 355-363. doi: $10.1080 / 00071660120103620$

Goerlich, V. C., Nätt, D., Elfwing, M., Macdonald, B., and Jensen, P. (2012). Transgenerational effects of early experience on behavioral, hormonal and gene expression responses to acute stress in the precocial chicken. Horm. Behav. 61, 711-718. doi: 10.1016/j.yhbeh.2012.03.006

Grippo, A. J., Gerena, D., Huang, J., Kumar, N., Shah, M., Ughreja, R., et al. (2007). Social isolation induces behavioral and neuroendocrine disturbances 
relevant to depression in female and male prairie voles. Psychoneuro Endocr. 32, 966-980. doi: 10.1016/j.psyneuen.2007.07.004

Hou, Y., Wang, L., Yi, D., Ding, B., Yang, Z., Li, J., et al. (2013). N-acetylcysteine reduces inflammation in the small intestine by regulating redox, EGF and TLR4 signaling. Amino Acids 45, 513-522. doi: 10.1007/s00726-012-1295-x

House, G. M., Sobotik, E. B., Nelson, J. R., and Archer, G. S. (2020a). Effect of the addition of ultraviolet light on broiler growth, fear, and stress response. J. Appl. Poult. Res. 29, 402-408. doi: 10.1016/j.japr.2020.01.003

House, G. M., Sobotik, E. B., Nelson, J. R., and Archer, G. S. (2020b). Effects of ultraviolet light supplementation on pekin duck production, behavior, and welfare. Animal 10:833. doi: 10.3390/ani10050833

Huth, J. C., and Archer, G. S. (2015). Comparison of two LED light bulb to a dimmable CFL and their effects on broiler chicken growth, stress, and fear. Poult. Sci. 94, 2027-2036. doi: 10.3382/ps/pev215

James, C., Asher, L., Herborn, K., and Wiseman, J. (2018). The effect of supplementary ultraviolet wavelengths on broiler chicken welfare indicators. Appl. Anim. Behav. Sci. 209, 55-64. doi: 10.1016/j.applanim.2018.10.002

Jovani, R., and Rohwer, S. (2017). Fault bars in bird feathers: mechanisms, and ecological and evolutionary causes and consequences. Biol. Rev. 92, 1113-1127. doi: 10.1111/brv.12273

Kannan, G., and Mench, J. A. (1996). Influence of different handling methods and crating periods on plasma corticosterone concentrations in broilers. Br. Poult. Sci. 37, 21-31. doi: 10.1080/00071669608417833

Kestin, S. C., Gordon, S., Su, G., and Sorensen, P. (2001). Relationships in broiler chickens between lameness, live weight, growth rate and age. Vet. Record 148, 195-197. doi: 10.1136/vr.148.7.195

Kokoszynski, D., Bernacki, Z., Saleh, M., Steczny, K., and Binkowska, M. (2017). Body conformation and internal organs characteristics of different commercial broiler lines. Braz. J. Poult. Sci. 19, 47-52. doi: 10.1590/1806-9061-2016-0262

Kristensen, D. H., Perry, G., Prescott, N., Ladewig, J., Ersbøll, A., and Wathes, C. (2006). Leg health and performance of broiler chickens reared in different light environments. Br. Poult. Sci. 47, 257-263. doi: 10.1080/00071660600753557

LaBrash, L. F., and Scheideler, S. E. (2005). Farm feather condition score survey of commercial laying hens. J. Appl. Poult. Res. 14, 740-744. doi: $10.1093 /$ japr/14.4.740

Lan, Y., Verstegen, M., Tamminga, S., and Williams, B. (2005). The role of the commensal gut microbial community in broiler chickens. Worlds Poult. Sci. J. 1, 95-104 doi: 10.1079/WPS200445

Lara, L. J., and Rostagno, M. H. (2013). Impact of heat stress on poultry production. Animal 3, 356-369 doi: 10.3390/ani3020356

Laudadio, V., Passantino, L., Perillo, A., Lopresti, G., Passantino, A., Khan, R., et al. (2012). Productive performance and histological features of intestinal mucosa of broiler chickens fed different dietary protein levels. Poult. Sci. 91, 265-270. doi: $10.3382 /$ ps.2011-01675

Lewis, P. D., and Morris, T. R. (1998). Responses of domestic poultry to various light sources. Worlds Poult. Sci. J. 54, 7-25. doi: 10.1079/WPS19980002

Li, M., Gao, Y., Lan, G., and Gu, Z. (2014). Effects of ultraviolet-B radiation on immunity and carcass characteristics in quail. J. Appl. Poult. Res. 23, 429-436. doi: 10.3382/japr.2013-00919

Lindqvist, C., Janczak, A. M., Nätt, D., Baranowska, I., Lindqvist, N., Wichman, A., et al. (2007). Transmission of stress-induced learning impairment and associated brain gene expression from parents to offspring in chickens. PLoS ONE 2:364. doi: 10.1371/journal.pone.0000364

Lupien, S. J., McEwen, B. S., Gunnar, M. R., and Heim, C. (2009). Effects of stress throughout the lifespan on the brain, behaviour and cognition. Nat. Rev. Neurosci. 10, 434-445. doi: 10.1038/nrn2639

Maddocks, S. A., Cuthill, I. C., Goldsmith, A. R., and Sherwin, C. M. (2001). Behavioural and physiological effects of absence of ultraviolet wavelengths for domestic chicks. Anim. Behav. 62, 1013-1019. doi: 10.1006/anbe.2001.1842

Mendoza, S. P., and Mason, W. A. (1986). Parental division of labour and differentiation of attachments in a monogamous primate (Callicebus moloch). Anim. Behav. 34, 1336-1347 doi: 10.1016/S0003-3472(86)80205-6

Moussa, M., Babilé, R., Fernandez, X., and Rémignon, H. (2007). Biochemical and biomechanical properties of tendons in two commercial types of chickens. Animal 1, 983-988. doi: 10.1017/S1751731107000183

Norman, G. J., Karelina, K., Morris, J. S., Zhang, N., Cochran, M., and DeVries, A. C. (2010). Social interaction prevents the development of depressive-like behavior post nerve injury in mice: a potential role for oxytocin. Psychosom. Med. 72, 519-526. doi: 10.1097/PSY.0b013e3181de8678

Olanrewaju, H., Miller, W., Maslin, W., Collier, S., Purswell, J., and Branton, S. (2016). Effects of light sources and intensity on broilers grown to heavy weights. Part 1: growth performance, carcass characteristics, and welfare indices. Poult. Sci. 95, 727-735. doi: 10.3382/ps/pev360

Prakatur, I., Miskulin, M., Pavic, M., Marjanovic, K., Blazicevic, V., Miskulin, I., et al. (2019). Intestinal morphology in broiler chickens supplemented with propolis and bee pollen ivana. Animal 9:301. doi: 10.3390/ani9060301

Rault, J. L., Clark, K., Groves, P. J., and Cronin, G. M. (2016). Light intensity of 5 or 20 lux on broiler behavior, welfare and productivity. Poult. Sci. 96, 779-787. doi: $10.3382 / \mathrm{ps} /$ pew 423

RSPCA (2017). RSPCA Welfare Standards for Laying Hens. Horsham; West Sussex.

Rukstalis, M., and French, J. A. (2005). Vocal buffering of the stress response: exposure to conspecific vocalizations moderates urinary cortisol excretion in isolated marmosets. Horm. Behav. 47, 1-7 doi: 10.1016/j.yhbeh.2004.09.004

Rutten, M., Leterrier, C., Constantin, P., Reiter, K., and Bessei, W. (2002). Bone development and activity in chickens in response to reduced weight-load on legs. Anim. Res. 51, 327-336. doi: 10.1051/animres:2002027

Sabet Sarvestani, F., Rahmanifar, F., and Tamadon, A. (2015). Histomorphometric changes of small intestine in pregnant rat. Vet. Res. Forum 6, 69-73.

Salmeto, A. L., Hymel, K. A., Carpenter, E. C., Brilot, B. O., Bateson, M., and Sufka, K. J. (2011). Cognitive bias in the chick anxiety-depression model. Brain Res. 1373, 124-130. doi: 10.1016/j.brainres.2010.12.007

Samanya, M., and Yamauchi, K. (2002). Histological alterations of intestinal villi in chickens fed dried Bacillus subtilis var. natto. Comp. Biochem. Physiol. A Mol. Integr. Physiol. 133, 95-104. doi: 10.1016/S1095-6433(02)00121-6

Sanotra, G. S., Lund, J. D., Ersbøll, A. K., Petersen, J. S., and Vestergaard, K. S. (2001). Monitoring leg problems in broilers: a survey of commercial broiler production in Denmark. World's Poult. Sci. J. 57, 55-69. doi: 10.1079/WPS20010006

SAS Institute Inc. (2012). Statistical Analysis Systems STAT User's Guide. Version 9.4 ed. Cary, NC.

Slominski, A. T., Janjetovic, Z., Fuller, B. E., Zmijewski, M. A., Tuckey, R. C., Nguyen, M. N., et al. (2010). Products of vitamin D3 or 7-dehydrocholesterol metabolism by cytochrome P450scc show anti-leukemia effects, having low or absent calcemic activity. PLoS ONE. 5:3. doi: 10.1371/journal.pone.0009907

Smith, A. S., Birnie, A. K., and French, J. A. (2011). Social isolation affects partner-directed social behavior and cortisol during pair formation in marmosets, Callithrix geoffroyi. Physiol. Behav. 104, 955-961. doi: 10.1016/j.physbeh.2011.06.014

Sobotik, E. B., Nelson, J. R., and Archer, G. S. (2019). How does ultraviolet light affect layer production, fear, and stress. Appl. Anim. Behav. Sci. 223:104926. doi: 10.1016/j.applanim.2019.104926

Soliman, F. N., and El-Sabrout K. (2020). Light wavelengths/colors: Future prospects for broiler behavior and production. J. Vet. Behav. 36, 34-39. doi: 10.1016/j.jveb.2019.10.014

Sufka, K. J., Feltenstein, M. W., Warnick, J. E., Acevedo, E. O., Webb, H. E., Cartwright, C., et al. (2006). Modeling the anxiety-depression continuum hypothesis in domestic fowl chicks. Behav. Pharm. 17, 681-689. doi: 10.1097/FBP.0b013e3280115fac

Tufarelli, V., Desantis, S., Zizza, S., and Laudadio, V. (2012). Performance, gut morphology and carcass characteristics of fattening rabbits as affected by particle size of pelleted diets. Arch. Anim. Nutr. 64, 373-382. doi: 10.1080/1745039X.2010.496945

Veleva, B. I., Caljouw, M. A., van der Steen, J. T., Mertens, B. J., Chel, V. G., and Numans, M. E. (2020). The effect of ultraviolet B irradiation compared with oral vitamin D supplementation on the well-being of nursing home residents with dementia: a randomized controlled trial. Int. J. Environ. Res. Public Health 17:1684. doi: 10.3390/ijerph17051684

Veleva, B. I., van Bezooijen, R. L., Chel, V. G., Numans, M. E., and Caljouw, M. A. (2018). Effect of ultraviolet light on mood, depressive disorders and wellbeing. Photodermat. Photoimmuno. Photomed. 34, 288-297. doi: 10.1111/phpp. 12396

Ventura, B. A., Siewerdt, F., and Estevez, I. (2010). Effects of barrier perches and density on broiler leg health, fear, and performance. Poult. Sci. 89, 1574-1583. doi: $10.3382 /$ ps.2009-00576 
Warnick, J. E., Huang, C. J., Acevedo, E. O., and Sufka, K. J. (2009). Modelling the anxiety-depression continuum in chicks. J. Psychopharmacol. 23, 143-156. doi: $10.1177 / 0269881108089805$

Weimer, S. L., Wideman, R. F., Scanes, C. G., Mauromoustakos, A., Christensen, K. D., and Vizzier-Thaxton, Y. (2018). An evaluation of methods for measuring stress in broiler chickens. Poult. Sci. 97, 3381-3389. doi: 10.3382/ps/pey204

Weldon, K. B., Fanson, K. V., and Smith, C. L. (2016). Effects of isolation on stress responses to novel stimuli in subadult chickens (Gallus gallus). Ethology 122, 818-827 doi: 10.1111/eth.12529

Westenbroek, C., Den Boer, J. A., Veenhuis, M., and Ter Horst, G. J. (2004). Chronic stress and social housing differentially affect neurogenesis in male and female rats. Brain Res. Bull. 64, 303-308. doi: 10.1016/j.brainresbull.2004.08.006

Zhang, L. X., Shi, Z. X., Wang, X. Y., Geng, A. L., and Li, B. M. (2006). Effects of ultraviolet radiation on skeleton development of broiler chickens. Agric. Sci. China 5, 313-331. doi: 10.1016/S1671-2927(06)60055-2

Zulkifli, I. (2013). Review of human-animal interactions and their impact on animal productivity and welfare. J. Anim. Sci. Biotechnol. 4:25. doi: 10.1186/2049-1891-4-25
Conflict of Interest: The authors declare that the research was conducted in the absence of any commercial or financial relationships that could be construed as a potential conflict of interest.

Publisher's Note: All claims expressed in this article are solely those of the authors and do not necessarily represent those of their affiliated organizations, or those of the publisher, the editors and the reviewers. Any product that may be evaluated in this article, or claim that may be made by its manufacturer, is not guaranteed or endorsed by the publisher.

Copyright (C) 2022 Ogbonna, Chaudhry and Asher. This is an open-access article distributed under the terms of the Creative Commons Attribution License (CC BY). The use, distribution or reproduction in other forums is permitted, provided the original author(s) and the copyright owner(s) are credited and that the original publication in this journal is cited, in accordance with accepted academic practice. No use, distribution or reproduction is permitted which does not comply with these terms. 